\title{
EXPERIMENTAL INVESTIGATION AND FEM MODELING OF GLUED TIMBER CONNECTIONS WITH SLOTTED-IN STEEL PLATES
}

\author{
Svitlana SHEKHORKINA ${ }^{1 *}$, Alexander KESARIISKY ${ }^{2}$, Mykola MAKHINKO ${ }^{1}$, Tetiana NIKIFOROVA ${ }^{1}$, Oleksandr SAVYTSKYI ${ }^{1}$
}

\section{Abstract}

The study is focused on the mechanical behavior and finite element method (FEM) modeling of glued timber dowel connections with slotted-in steel plates. Standard tests accompanied by a physical optics investigation method were used in order to obtain information about the mechanical properties and stress-strain behavior of glued timber dowel connections with slotted-in steel plates. As such a methodology provides information on the stress-strain state over the surface of a connection, it was used as a verification criterion for a 3D finite-element model. Small-scale glued timber dowel connections with slotted-in steel plates were tested in parallel-to-grain tension to investigate their load-carrying capacity and the load-slip performance of the connection. A three-dimensional finite-element model of the glued timber dowel connections with slotted-in steel plates was developed using existing FE software and verified using the holographic interferograms obtained during step-by-step loading as well as the test results.

\section{Address}

1 Dept. of Reinforced Concrete and Stone Structures, State Higher Education Establishment "Pridniprovs'ka State Academy of Civil Engineering and Architecture", Dnipro, Ukraine

2 Laboratory of Complex Technologies Ltd, Pavlograd, Ukraine

* Corresponding author: svetlana.svt.28@gmail.com

\section{Key words}

- Glued timber,

- Connections with slotted-in plates,

- Holographic laser interferometry.

\section{INTRODUCTION}

Joints in timber structures are an important part and, at the same time, the weakest point in a whole structure. Dowel type connections (nails, dowels etc.) are one of the most popular types of joints in timber construction. To increase the load-carrying capacity of a dowel-type joint, it is often used in combination with slottedin steel plates. The dowels transfer loads between the steel plates and the timber elements, and the steel plates are used to transfer the load between members. The strength and deformability of doweltype joints of elements made of solid or glued timber depend on the physical and mechanical characteristics of the wood, the embedding properties, and the characteristics of the connectors (dowels and plates). Together, these parameters define the general load-carrying capacity and load-slip performance of the connection.

The behavior of the joint can be studied through experiments as well as by means of a Finite Element analysis. Modern engineering software allows for the creation of three-dimensional models with precise geometry that take into account a wide range of physical and mechanical properties and the behavior of the elements in the connection under the load. The initial data for creating computation models, in addition to the geometric parameters, are the characteristics of the material of the structural elements. While a dowel made of steel has an isotropic behavior, timber is an orthotropic material with different mechanical properties in three directions (longitudinal, radial, and tangential). Various material models for modeling timber connections have been proposed by many writers. For modeling wood many different approaches have been proposed, i.e., an orthotropic material theory for an elastic range (Bodig, 1982); an anisotropic plasticity model accounting for the nonlinear behavior of wood (Moses 2000); an orthotropic elasto-plastic material (Gečys et al., 2015), and a nonlinear elastic model based on the principles of continuum damage mechanics (Sandhaas, 2012). The elastic properties and strength properties of timber for a 3D model are determined by means of standard tests or are taken from the literature. These properties represent the average behavior of wood at 
a macroscopic level. According to (Hong, 2011), the timber around a dowel surface can be simulated as a material with different properties determined from embedment tests.

A broad database on the results of the experimental assessment of the mechanical behavior of timber material and joints exists. It covers the issues of load-slip behavior, embedment properties, failure modes, and the strength of different types of timber and joints. Nevertheless, a combination of the standard test methods with nonstandard techniques (e.g., physical optics) provides more information about the stress-strain state over the surface or the volume of the single elements or the connection. Information obtained from such experiments can be used to verify the connection model, simplify the simulation techniques, etc.

\section{EXPERIMENTAL PROGRAM}

\subsection{Embedment tests}

Tests according to EN383 were carried out to arrive at an assessment of the strength and deformation properties of timber in the area of the interaction between the timber and dowel. The experiment included testing 4 samples. Each specimen was made of Scotch pine and had a prismatic form; the dimensions of the cross-section are $120 \times 30 \mathrm{~mm}$ with a height of $180 \mathrm{~mm}$. A dowel with a $12 \mathrm{~mm}$ diameter was put in a pre-drilled hole with a diameter of $13 \mathrm{~mm}$ in each sample.

The samples (D0, D1, D2, D3) were tested with an application of an adapted method of optical physics (laser interpherometry), which allows for obtaining data about the actual character of an interaction between the elements in the connection in the form of displacement fields over the surface of the specimen (interpherograms). The data obtained can be used for the calibration and verification of the calculation model that is developed in the next step. A general view of the mounted equipment for the embedment tests with the registration

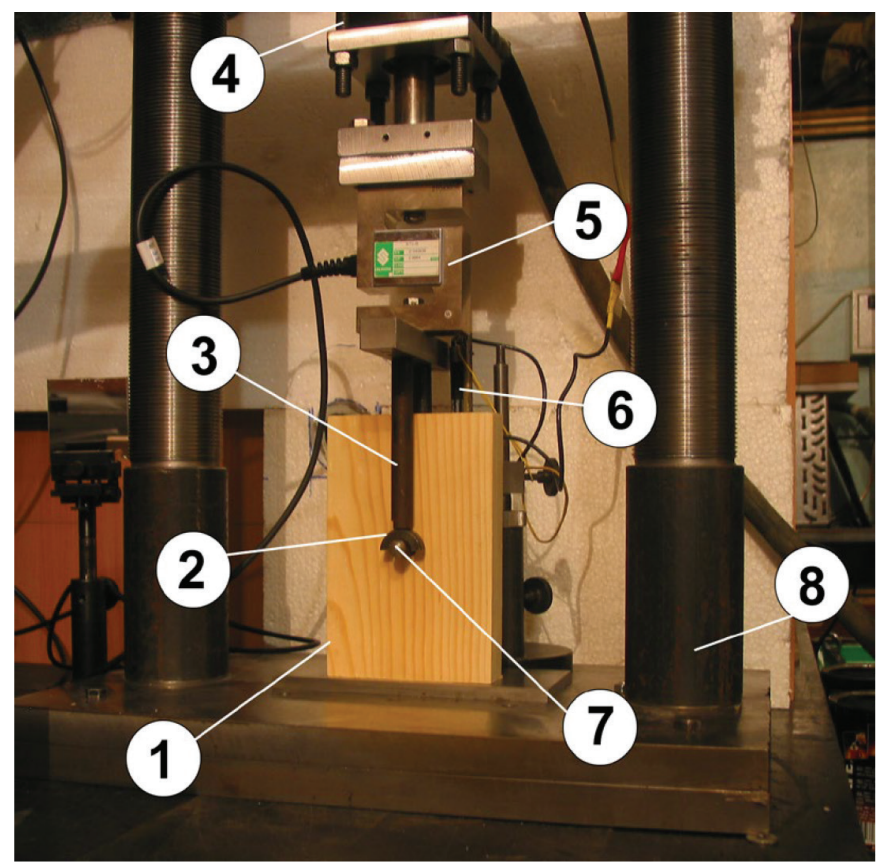

Fig. 1 A general view of the mounted equipment for the embedment tests: 1 -sample, 2-lodgment of the dowel, 3 -stock for force transfer, 4 - hydraulic cylinder, 5 - force sensor STC-5000 kg , 6 longitudinal displacement sensor (Honeywell Sensing and Control LTW05N05KF5C), 7 - dowel, 8 -loading equipment of the displacement fields by the laser interpherometry method is shown in Fig. 1. A general scheme of the mounted equipment is shown in Fig. 2.

Loading of the sample in a parallel-to-grain direction was carried out step-by-step until failure. The registration of the interferograms was performed at each stage of loading. The interferograms obtained clearly show the area of the interaction between the dowel and the timber (Fig. 3a). The destruction begins with the visible "flattening" of the fibers of the wood beneath the surface of the dowel. Near the failure stage the level of the micro-destruction began to affect the bearing capacity of the sample, and the formation of cracks began (the area of the loss of interference fringes).

The load-displacement diagram for the samples investigated is shown in Fig. 3b. The diagram clearly identifies the area that corresponds to the maximum load. This area is followed by a gradual increase in displacements without a change in load, which is caused by the destruction of the wood's microstructure and the formation and growth of cracks below the surface of the dowel, which correspond to the destruction of the sample. The maximum load was reached within 2.5-3.5 $\mathrm{mm}$ of the vertical displacement. The embedding strength was calculated according to the formulas given in EN383. The values of the maximum loads and embedding strength obtained are presented in Tab. 1.

Tab. 1 Values of the maximum loads and embedding strength.

\begin{tabular}{lll}
\hline Sample & Maximum load, $\mathbf{k N}$ & Embedding strengths, fh, MPa \\
\hline D0 & 19.5 & 54.2 \\
D1 & 14 & - \\
D2 & 21 & 58.3 \\
D3 & 20 & 55.5 \\
\hline
\end{tabular}

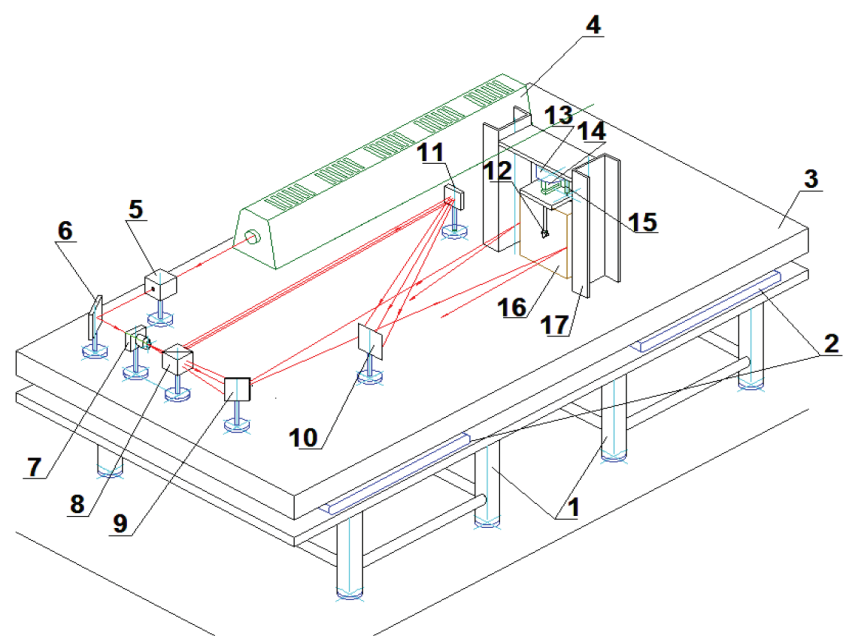

Fig. $23 D$ scheme of the equipment for the registration of the holographic interferograms: 1- equipment supports; 2 - pneumodamper pads; 3 - vibroprotected platform; 4 - laser; 5 light shutter; 6, 9, 11 - mirrors; 7 - micro lens; 8 - beam splitter; 10 - photographic plate with a holder; 12-dowel; 13- hydraulic cylinder; 14 -force sensor; 15 - longitudinal displacement sensor; 16 - sample investigated; 17 - loading device 
a)
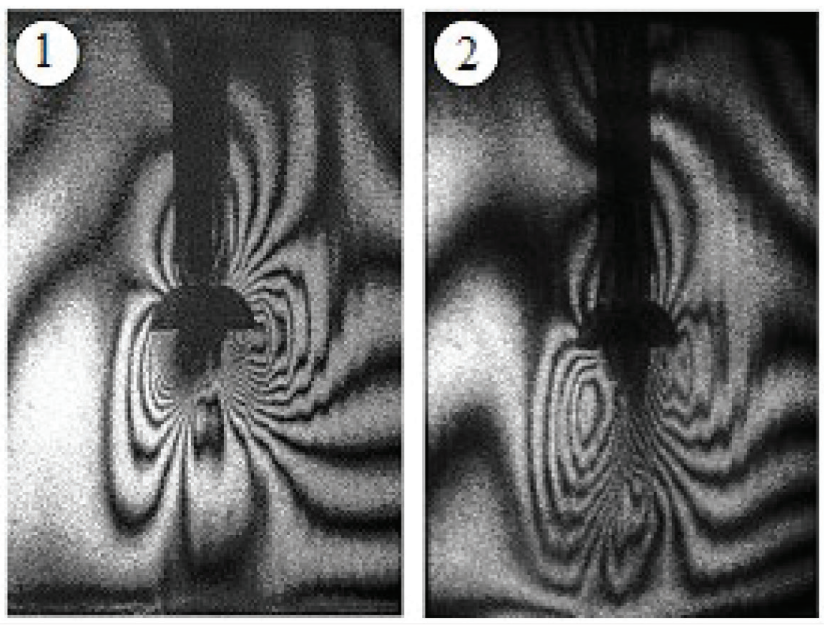

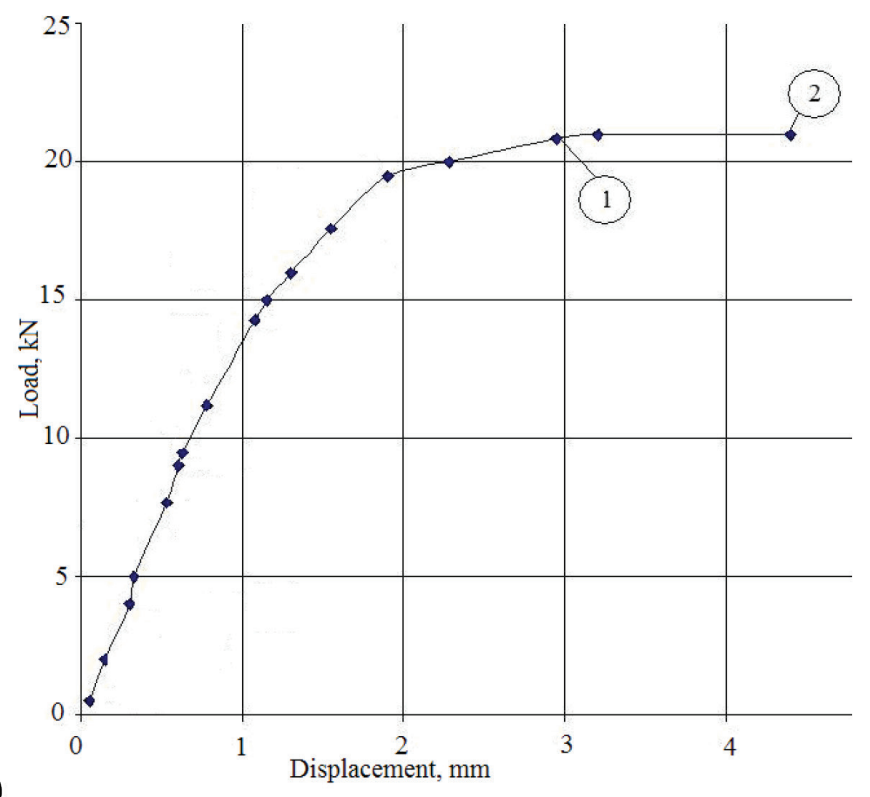

Fig. 3 Interferograms (a) and load-displacement diagram (b) obtained during step-by-step loading

\subsection{Small-scale glued timber dowel connections with slotted-in steel plates}

The small-scale connection for the test in a parallel-to-grain tension was constructed of a glued laminated timber element with cross-sectional dimensions of $120 \times 120 \mathrm{~mm}$ with a slotted-in steel plate $6 \mathrm{~mm}$ thick and $80 \mathrm{~mm}$ wide. The transfer loads between the steel plate and the timber element were provided by dowels with a diameter of $12 \mathrm{~mm}$. Equipment providing loading by tensile force from 0 to $150 \mathrm{kN}$ was developed and manufactured (Fig. 4). The registration of the load acting on the connection was carried out by monitoring the pressure in the hydraulic system. The displacements were obtained by a longitudinal displacement sensor used for the embedment test. The load-displacement curve for the tension test with a designation of the characteristic areas of the connection's behaviour is presented in Fig. 5. Considering the design requirements, the timber connection

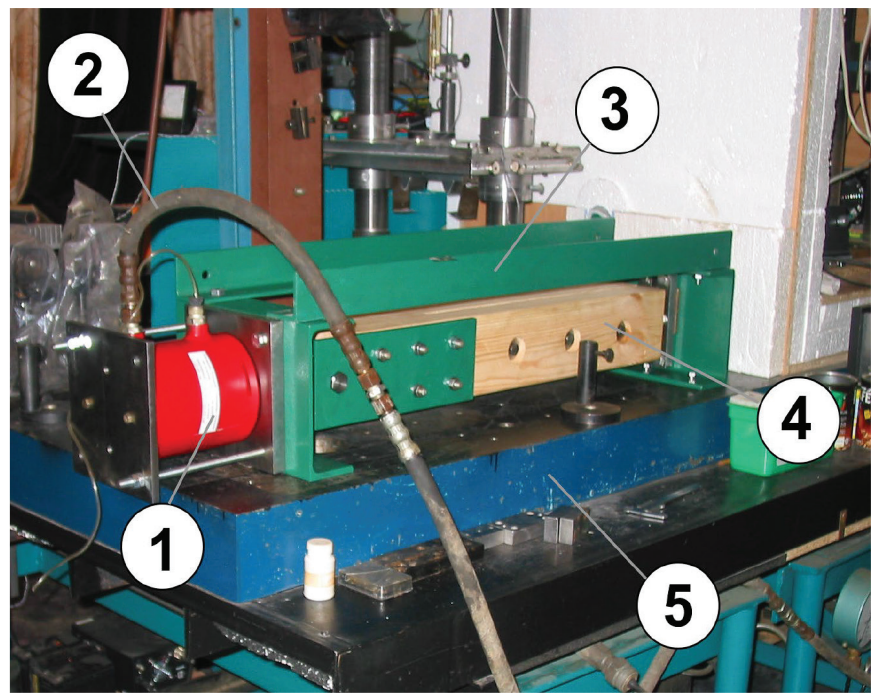

Fig. 4 A general view of the mounted equipment for the tension test of the connection with slotted-in steel plates: 1 - hydraulic cylinder; 2- hydraulic hose; 3 -testing rig; 4- connection investigated; 5 base plate remains workable if the mutual residual displacements of the elements do not exceed $5 \mathrm{~mm}$. Based on this criterion, it can be assumed that the allowable tensile load for the connection studied is $60-80 \mathrm{kN}$. As can be seen from the graph, this range of loads corresponds to a linear segment of the load-displacement curve.

\section{FEM MODELING}

The development of the finite element model for the glued timber connection with the slotted-in steel plates was carried out in two stages. The modeling was performed using LIRA-SAPR commercial software. Universal spatial eight and six-node finite elements with the possibility of taking the orthotropy into account were used to create 3D models. In order to simplify the calculation model, the timber was considered as an elastic orthotropic material.

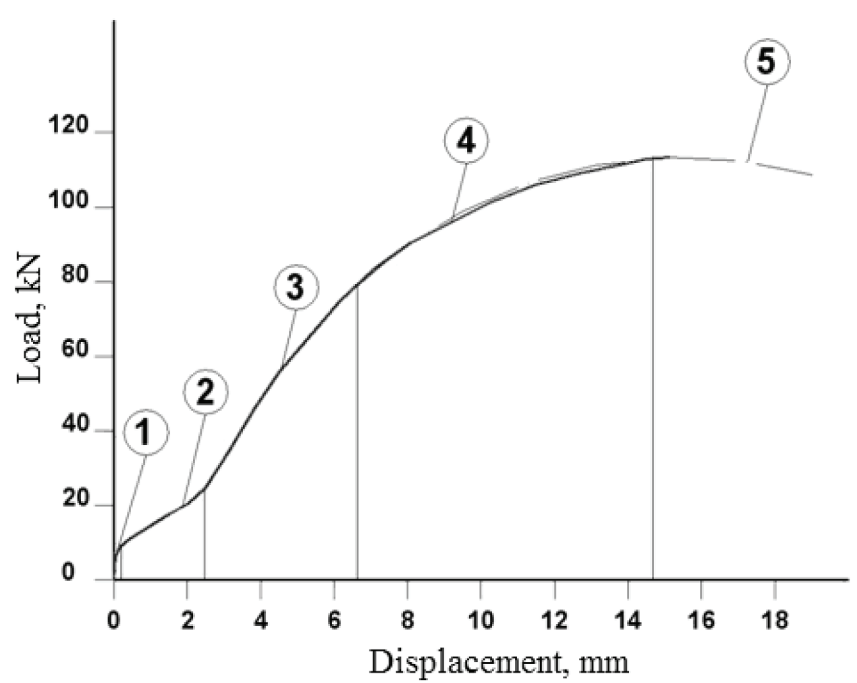

Fig. 5. Load-displacement curve for the tension test of the connection with the slotted-in steel plates: 1 -micro-roughness pressing, 2 - contact pad formation, 3 - linear deformation, 4 - nonlinear deformation (local destruction), 5 - destruction of the connection (by extrapolation) 


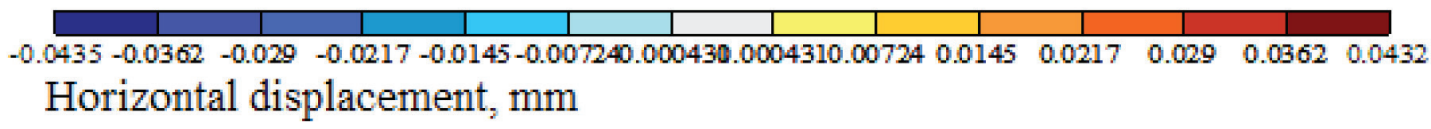

a)

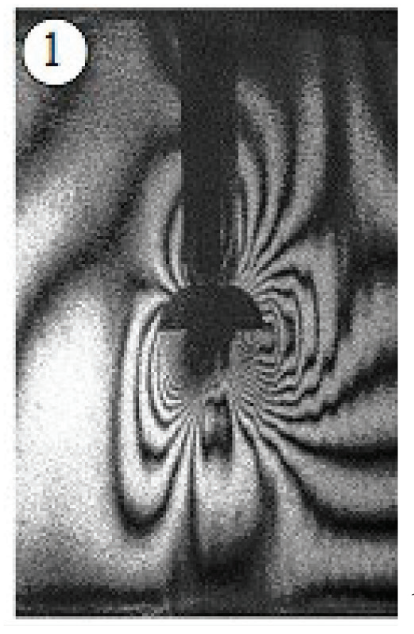

b)

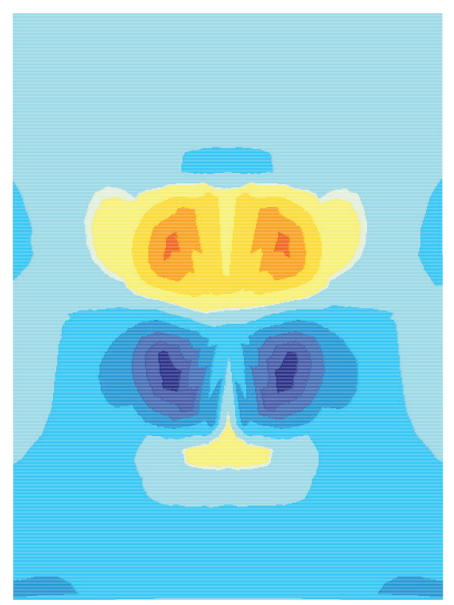

Fig. 6 Comparison of the surface interferogram (a) at the stage near the destruction of the sample with the displacement isofields (b)

Tab. 2 Maximum values of the displacements and stresses obtained by the modeling and experiment for the embedment tests

\begin{tabular}{l|l|l|l}
\hline & $\begin{array}{l}\text { Horizontal } \\
\text { displacement, } \mathbf{~ m m}\end{array}$ & $\begin{array}{l}\text { Vertical } \\
\text { displacement, mm }\end{array}$ & Stresses, MPa \\
\hline Experiment & $0.04 . .0 .047$ & $2.5 \ldots 3.8$ & 56 \\
Model & 0.03 & 3.15 & 51.8 \\
\hline
\end{tabular}

Modeling the embedment test was first carried out in order to determine and calibrate the values of the physical and mechanical characteristics of the components and the parameters of the zone of interaction of the wood and dowel. The FEM simulation of the embedment tests was based on the approach proposed in (Hong, 2011). It is assumed that in a certain area along the perimeter of a dowel, a wood foundation is formed with characteristics different from the deformation characteristics of the wood of the whole element. According to the interpherograms, the wood foundation area obtained has an elliptical form with the longest diameter approximately $3.5-4 \varnothing$ and the shortest diameter $2-2.5 \varnothing$ (where $\varnothing$ is the bolt diameter).

The necessary physical values for the wood and the wood foundation were determined according to the formulas given in [Hong, 2007], the results of the experiments carried out, and the existing data. The following dependencies for the deformation parameters were applied: $E_{1} v_{12}=E_{2} v_{21}, E_{1} v_{13}=E_{3} v_{31}, E_{2} v_{23}=E_{3} v_{32}\left(E_{i}-\right.$ elastic modulus, $v_{i j}$ - Poisson's ratio). The elastic modules obtained are the following: $E_{l w}=2016 \mathrm{MPa}, E_{2 w}=12600 \mathrm{MPa}, E_{3 w}=2016 \mathrm{MPa}$ (for the wood); $E_{1 w f}=168 \mathrm{MPa}, E_{2 w f}=1050 \mathrm{MPa}, E_{3 w f}=100 \mathrm{MPa}$ (for the wood foundation). The shear modules: $G_{12 w}=G_{3 l w}=760 \mathrm{MPa}$, $G_{23 w}=1230 \mathrm{MPa}$ (for the wood); $G_{12 w f}=G_{31 w f}=50 \mathrm{MPa}, G_{23 w f}=110 \mathrm{MPa}$ (for the wood foundation). The density of the wood was accepted as $550 \mathrm{~kg} / \mathrm{m}^{3}$. The Poisson's ratios for the 3D model were $v_{12}=0.5$, $v_{21}=0.08, v_{23}=0.3, v_{32}=0.5, v_{13}=0.045$ and $v_{31}=0.469$. The steel dowel in the connection was modelled as an isotropic elastic material with $E_{s}=210000 \mathrm{MPa}, v_{s}=0.3$ and $\rho_{s}=7850 \mathrm{~kg} / \mathrm{m}^{3}$.

Tab. 3 The values of the displacements obtained by the modeling and experiment for the connection tests

\begin{tabular}{l|l|l|l}
\hline & Experiment & Model & Difference, $\%$ \\
\hline Vertical displacement, $\mathrm{mm}$ & 4.8 & 3.97 & $17 \%$ \\
\hline
\end{tabular}

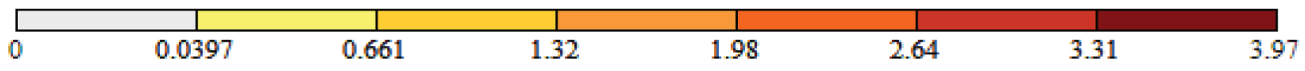

Vertical displacement, $\mathrm{mm}$

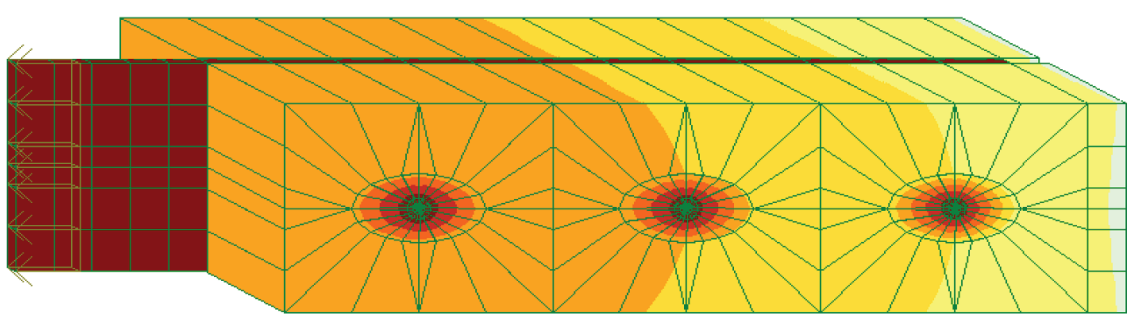

Fig. 7. Vertical displacement isofield 
Verification of the model was performed by comparing the isofields of the displacements perpendicular to the plane of the sample with the interferograms of the deformed surface (Fig. 6), as well as the values of the vertical displacement and stresses under the surface of the dowel obtained by testing. A comparison of the surface interferogram at the stage near the destruction of the sample with displacement isofields has showed that the nature of the deformation of the calculation model is close to the experimental model. The maximum values of the displacements and stresses obtained by the modeling and experiment are given in Tab. 2.

The theoretical values of the horizontal and vertical displacements obtained are close to the experimental ones. The stress value under the surface of the dowel according to the simulation results differs from the average experimental value by $7.5 \%$.

Further, the behaviour of the connection under a tensile load was modeled. The material characteristics of the components of the connection and the parameters of the zone of the interaction of the wood and dowel were similar to the characteristics for modeling the embedment test. A tensile load equal to $60 \mathrm{kN}$ was applied to the connection model. The vertical displacement was obtained from the simulation (Tab. 3); the values differ from the test results by $17 \%$.

\section{CONCLUSIONS}

The experimental assessment and the general proposals for the finite element modeling of the glued laminated timber connections with slotted in plates were presented.

The experimental program included determination of the mechanical and embedding properties of glued timber made of Scotch pine wood. Small-scale glued timber dowel connections with slotted-in steel plates were tested in a tension parallel-to-grain to investigate the load-carrying capacity and load-slip performance of the connection. The paper demonstrates the benefits of the complex experimental investigation of the glued laminated timber connection and its separate components, which include the standard techniques and the holographic laser interferometry method. The application of this method permits obtaining information about the actual stressstrain state of the samples. The experimental data obtained were used for verification of the FEM model.

The embedment test was modeled using existing FE software to specify the material properties for a 3D finite-element model of the connection. Afterwards, the 3D finite-element model of the glued timber dowel connections with slotted-in steel plates was developed and analyzed in a tension parallel to the grain.

The 3D finite-element model obtained is based on the known material properties and can be used for a conservative prediction of the load-carrying capacity of glued timber dowel connections with slotted-in steel plates. A further challenge to improve the proposed model is a consideration of the nonlinear behaviour of glued laminated timber connections with slotted-in plates. 


\section{REFERENCES}

Bodig J. - Jayne B. A. (1982) Mechanics of wood and wood composite, Van Nostrand Reinhold, Inc.

Franke S. - Magnière N. (2014) Discussion of testing and evaluation methods for the embedment behaviour of connections, International Network on Timber Engineering Research - INTER, At Bath, UK, Vol. 2014.

Forest Products Laboratory (1999) Wood Handbook. Wood as an engineering material, Gen. Tech. Rep. FPL-GTR-113.

Gecys T. - Daniunas A. - Bader T. K. - Wagner L. - Eberhardsteiner J. (2015) $3 D$ finite element analysis and experimental investigations of a new type of timber beam-to-beam connection, Engineering Structures 86, pg. 134-145.
Hong J. - Barrett J. D. - Lam F. (2011) Three-dimensional finite element analysis of the Japanese traditional post-and-beam connection, J Wood Sci 57, pg. 119-125.

Moses D. M. (2000) Constitutive and analytical models for structural composite lumber with applications to bolted connections, $\mathrm{Ph} . \mathrm{D}$ dissertation, Department of Civil Engineering, The University of British Columbia, Vancouver, BC, Canada.

Sandhaas C. (2012) Mechanical behaviour of timber joints with slotted-in steel plates, Zutphen: Wohrmann. 